\title{
International Year of Chemistry 2011
}

SCS

$\checkmark$ Division of

Industrial Chemistry
Popular Scientific Papers

Presented by the Division of Industrial Chemistry

\section{A Streamlined Synthesis of Androstadiene C-17 Ester Derivatives}

Fabrice Gallou*, Manuela Seeger-Weibel, and Daniel Lupp

${ }^{*}$ Correspondence: Dr F. Gallou, Chemical and Analytical Development, Novartis Pharma AG, CHBS, WSJ-145.7.52, Novartis Campus, CH-4056 Basel

Tel.: +41 6132499 11, E-mail: fabrice.gallou@novartis.com

Abstract: The development of a fully telescoped synthesis of a derivative of androstadiene $\mathrm{C}-17$ esters made from epoxyparamethasone was demonstrated. This streamlining allowed for the elimination of isolation and solvent change after each synthetic step. Thus it not only drastically reduced the solvent waste, but also minimized the potential exposure to highly active intermediates thereby increasing the overall yield. The intuitively obvious advantage inherent to lowering the number of solvents was illustrated by applying standard green metrics.

Keywords: Androstadiene - E-factor - Environmental impact . Process Mass Intensity · Reaction Mass Intensity · Telescope

\section{Introduction}

Inhaled corticosteroids (ICS) are clinically proven to be some of the most effective treatment for all levels of severity of asthma. In the course of our program on ICS, we became interested in derivatives of the readily available epoxyparamethasone 2. [1] Several candidates with substituents on the hydroxyl and ester anchors had shown remarkable potency. The synthetic approach of these derivatives was based on oxidative cleavage of the $\alpha$-hydroxyketone to the corresponding acid. ${ }^{[2]}$ The resulting acid was esterified and the free tertiary hydroxyl group was functionalized with diverse heterocyclic moieties. The synthesis was completed by acidic opening of the epoxide ring in stereoselective fashion to the $\alpha$-chloro derivatives. A model substrate $\mathbf{1}$ is described in the rest of the discussion to illustrate our newly developed process (Scheme 1), whereby the methyl ester resulting from cleavage of the $\alpha$-hydroxy ketone and the 3-methylthienyl-

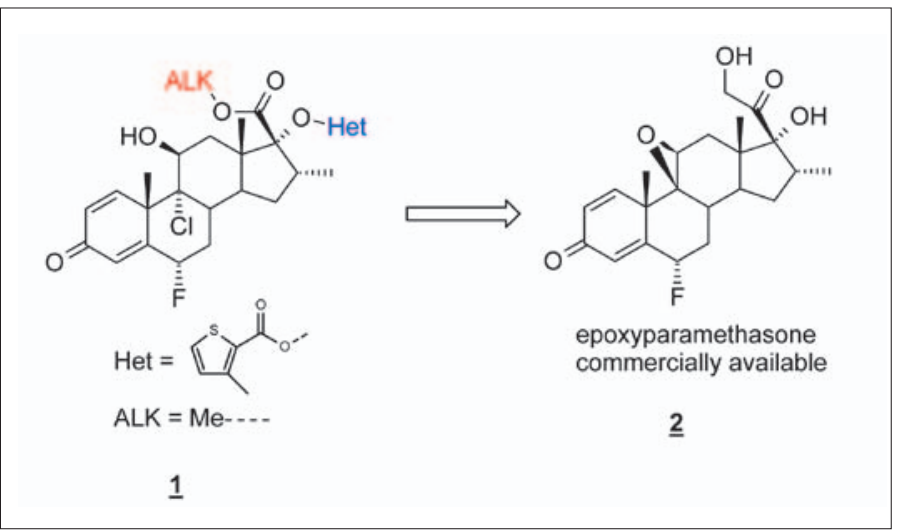

Scheme 1. Acidic opening of the epoxide ring in stereoselective fashion to the $\alpha$-chloro derivatives. 2-carboxylate moiety was used to cap the free hydroxyl group to the desired product $\mathbf{1}$, ready for final processing to the targeted solid state form.

The highly potent nature of this class of compounds prompted us to consider a fully streamlined process with minimal number of operations and open handling of solids. This is of particular advantage for large-scale processes when considered from health, safety and environmental perspectives. The present article describes our progress in this direction.

\section{Results}

\section{Oxidative Cleavage}

Our work started with an extensive screening of conditions for the selective oxidative cleavage of the $\alpha$-hydroxy ketone $\mathbf{2}$ (Scheme 2 ). Periodic acid was shown to be optimal for this transformation. Other catalytic methods led to, at best, mediocre selectivity and conversion. The safe temperature operating range was determined to be below $60{ }^{\circ} \mathrm{C}$ to avoid potential critical oxidation and explosions due to periodic acid. ${ }^{[3]}$ From all the reaction mixtures submitted for both dynamic and isothermal DSC analysis, an onset of decomposition was typically observed at around $100{ }^{\circ} \mathrm{C}$. The measurements showed that within 30 minutes at a temperature above $120^{\circ} \mathrm{C}$, a highly energetic decomposition was taking place (Fig. 1). ${ }^{[4]}$

A subsequent solvent screening revealed that only ethereal solvents such as THF or 2-methyltetrahydrofuran (2-MeTHF) could promote complete cleavage. All other solvents (aromatics, alkanes, chlorinated or highly polar solvents, water and phasetransfer catalysts) showed only partial or unselective reactivity within the safe operating range. ${ }^{[5]}$

The reported chemical incompatibility of periodic acid with most organic solvents ${ }^{[6]}$ prompted us to reduce the concentration of oxidizing agent in the organic phase by rendering the system biphasic through the addition of water. In the case of water-miscible organic solvents, an alkane co-solvent ( $c a$. 20\% depending on the solvent) was added to obtain a heterogeneous system. In all solvents except methanol, an incomplete conversion was observed. Recourse to methanol was however not an alternative as explosive methylperiodate could be formed. ${ }^{[7]}$ The use of a phase transfer catalyst was also not regarded as desirable as explosions have been reported. ${ }^{[8]}$

At the outcome of the screening, a mixture of THF/hexanes/water was shown to give the optimal results with complete conversion in about $6 \mathrm{~h}$. Interestingly, only marginal differences were observed when switching to the simpler 2-MeTHF/water solvent

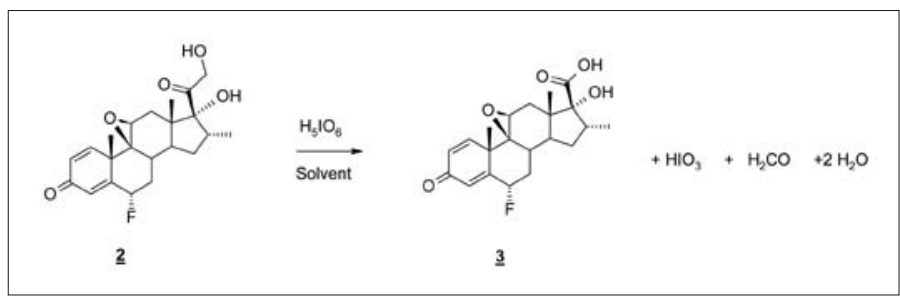

Scheme 2. Selective oxidative cleavage of the $\alpha$-hydroxy ketone. 


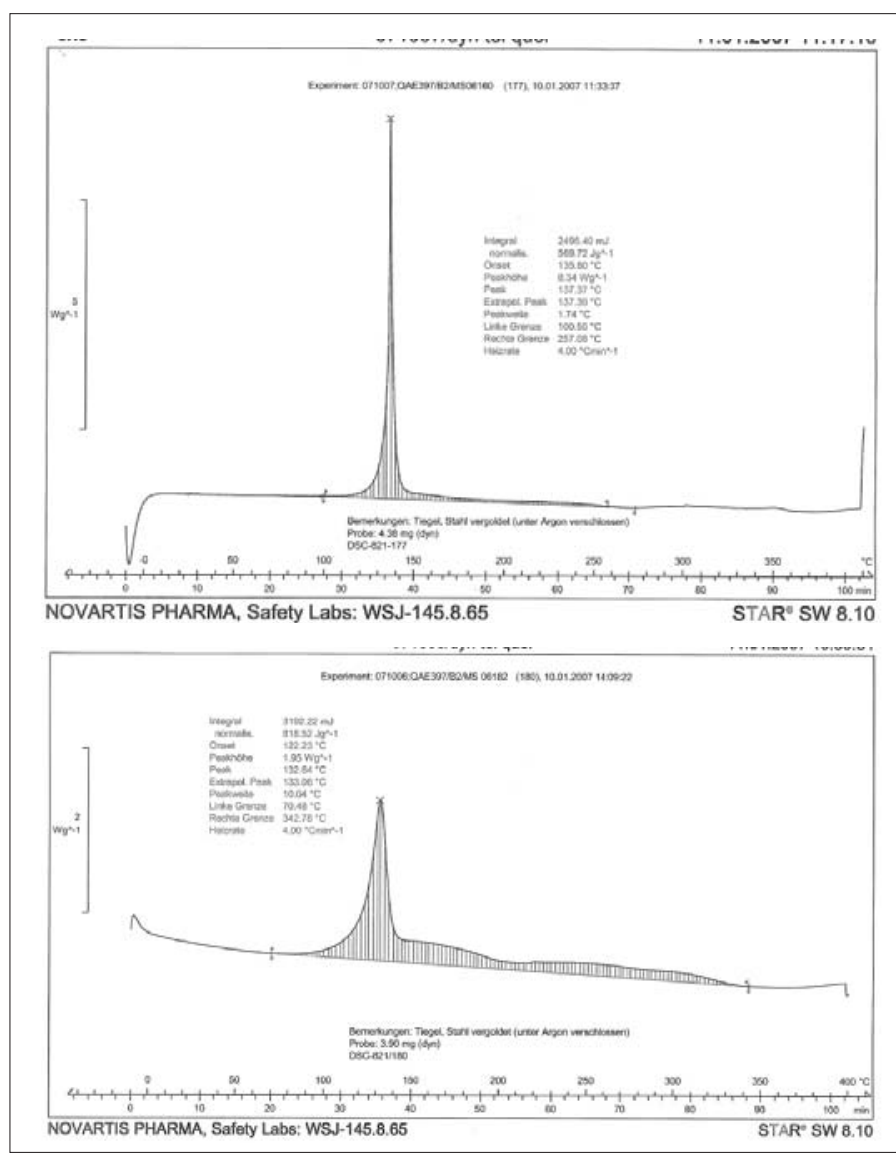

Fig. 1. Representative isothermal and dynamic differential scanning calorimetry curves.

system, which did not require the presence of an additional alkane solvent. The reaction rate was however reduced by a factor of almost 3 ( $c a .15 \mathrm{~h}$ for completion). ${ }^{[8]}$ This solvent system nevertheless sparked our interest as it would lead to multiple opportunities for the downstream process.

The difficulty to remove unreacted starting material prompted us to aim at full conversion in the oxidative cleavage. With the $\mathrm{MeTHF} /$ water solvent system, the excess of oxidizing agent could not be reduced to less than 1.1 equiv. as only incomplete conversion or poorly reproducible results were obtained in reasonable reaction times (less than $15 \mathrm{~h}$ ). A stoichiometry of periodic acid of 1.3 equiv. relative to the epoxyparamethasone starting material was therefore used for the further optimization (Table 1).

From a safety standpoint, the transformation was obviously of particular concern as it was associated with a high risk of peroxide formation when carried out in an ethereal solvent.

2-MeTHF is known to form two different classes of peroxides (Fig. 2). The first class, water-soluble, was regarded as more easily manageable. It could indeed be controlled by removal via aqueous washings. The second class, water-insoluble peroxides, is actually less well-documented and presented more safety concerns. Little is known about them apart from their qualitative solubilities in organic solvents. ${ }^{[9]}$

Table 1. Optimization of a periodic acid stoichiometry relative to epoxyparamethasone

$\begin{array}{ll}\text { Stoichiometry periodic acid } & \text { Results } \\ 0.95 \text { equiv. } & \text { incomplete conversion after } 2 \text { days } \\ 1.0 \text { equiv. } & \text { incomplete conversion after } 2 \text { days } \\ 1.1 \text { equiv. } & \text { complete conversion after } 24 \mathrm{~h} \\ 1.3 \text { equiv. } & \text { complete conversion after } 12 \mathrm{~h}\end{array}$

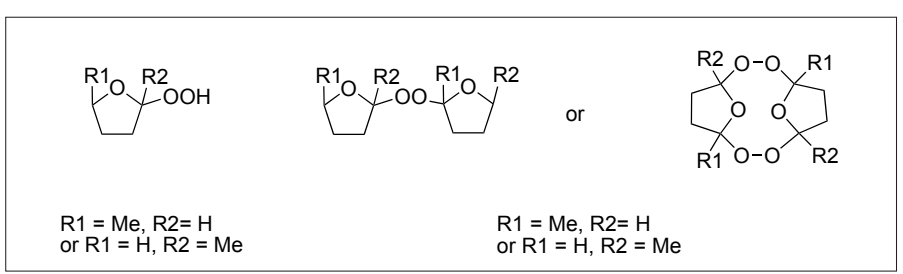

Fig. 2. Oxidative cleavage. Left: water-soluble hydroperoxide; right: water-insoluble ether peroxide.

Table 2. Peroxide content in the organic phase

\begin{tabular}{llllll} 
Entry & $\begin{array}{l}\text { Amount } \\
\text { periodic } \\
\text { acid }\end{array}$ & $\begin{array}{l}\text { Reaction } \\
\text { tempe- } \\
\text { rature }\end{array}$ & $\begin{array}{l}\text { Reac- } \\
\text { tion } \\
\text { time }\end{array}$ & $\begin{array}{l}\text { Content of } \\
\text { peroxide in } \\
\text { the organic } \\
\text { phase }\end{array}$ & $\begin{array}{l}\text { Content of per- } \\
\text { oxide in the or- } \\
\text { ganic phase af- } \\
\text { ter phosphinic } \\
\text { acid washing }\end{array}$ \\
\hline 1 & 1.1 equiv. & $23^{\circ} \mathrm{C}$ & $16 \mathrm{~h}$ & $101 \mathrm{ppm}$ & \\
2 & 1.1 equiv. & $35^{\circ} \mathrm{C}$ & $16 \mathrm{~h}$ & $99 \mathrm{ppm}$ & \\
3 & 1.3 equiv. & $23^{\circ} \mathrm{C}$ & $16 \mathrm{~h}$ & $88 \mathrm{ppm}$ & $<5 \mathrm{ppm}$ \\
4 & 1.3 equiv. $\quad 35^{\circ} \mathrm{C}$ & $16 \mathrm{~h}$ & $106 \mathrm{ppm}$ & \\
5 & 1.3 equiv. $23^{\circ} \mathrm{C}$ & $6 \mathrm{~h}$ & $66 \mathrm{ppm}$ & \\
Reaction conditions: $0.13 \mathrm{~g} / \mathrm{mL}$ of 2 in $2-\mathrm{MeTHF}$
\end{tabular}

The reactive system had been designed on purpose as a biphasic system in order to get a better phase separation and a lower content of periodic acid in the organic phase. After complete conversion, the excess of periodic acid and water-soluble peroxides were removed from the organic phase by aqueous washings and the peroxide content in the organic phase was measured (Table 2). ${ }^{[10]}$

In all cases, independent of the temperature or the stoichiometry of periodic acid, a content of about 100 ppm was observed. Only in the case of significantly reduced reaction time (entry $5,6 \mathrm{~h}$ reaction time instead of $16 \mathrm{~h}$ ), the content was lowered marginally (from $c a$. $100 \mathrm{ppm}$ to $66 \mathrm{ppm}$ ), presumably due to reduced peroxidation of the solvent itself. Eventually, the remaining peroxide could be removed by washing the organic layer with a $50 \%$ aqueous solution of phosphinic acid thereby reducing the peroxide content to less than $5 \mathrm{ppm}$. The use of aqueous solutions of sodium thiosulfate or sodium sulfite was not sufficient to reach the targeted levels of peroxides of less than $5 \mathrm{ppm}$. Overall, the desired oxidative cleavage product could be obtained in $94 \%$ assay yield and purity higher than $95 \%$. The high purity at this stage and the high potency of the intermediate prompted us to carry on the next step without isolation and further purification.

\section{Esterification Steps}

The subsequent esterification of the carboxylic acid required anhydrous conditions. While classical crystallization was a viable option, direct use of the crude product in solution was envisioned with an in situ drying process to minimize open handling of dried product. The newly identified solvent system now allowed us to proceed very efficiently via cycles of azeotropic distillations.[11] This drying procedure was used effectively on multi-kg scale on one of our targeted derivatives in the pilot plant. Once again, 2-MeTHF had turned out to be a superior alternative to THF due to the improved efficiency of the azeotropic distillation. ${ }^{[12]}$ The longer reaction times in 2-MeTHF were partially compensated by the reduced number of cycles and faster azeotropic drying. In addition, the process allowed for easier recycling of the solvent and minimization of the contaminated solvent waste.

For the esterification of the free tertiary hydroxyl group, the original process reported the use of toluene and THF as solvents for the formation of the activated acid chloride $\mathbf{4}$ and the subsequent 


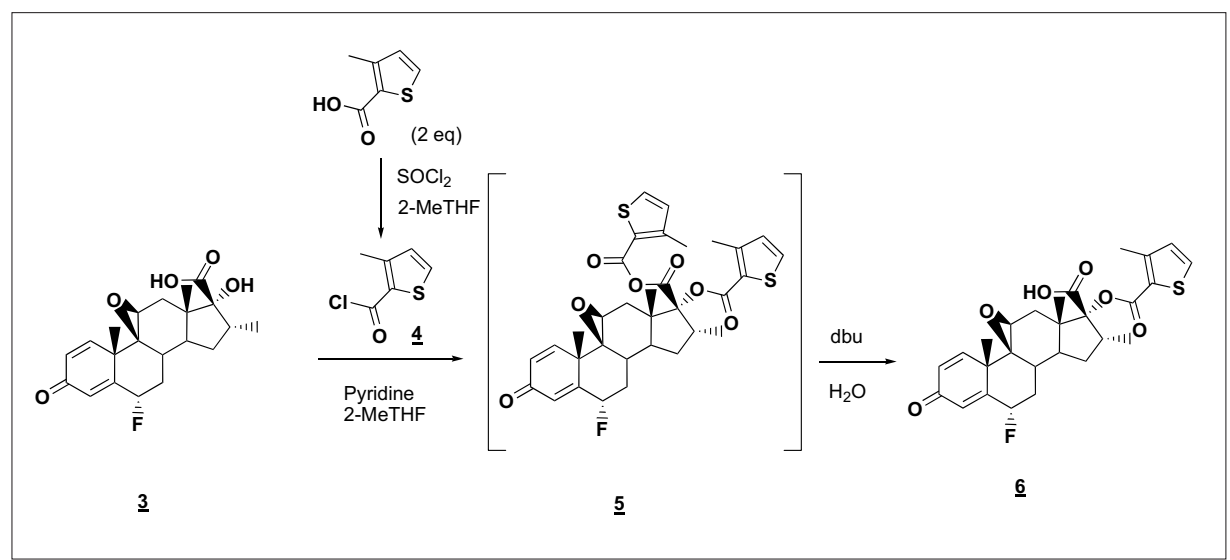

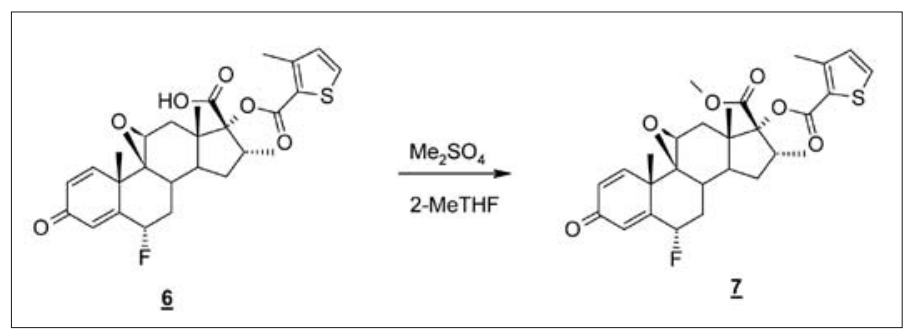

Scheme 4.

esterification to 6 (Scheme 3 ). This was rapidly streamlined and adjusted to better align with our overall process strategy by converting the 3-methylthienyl-2-carboxylic acid into the corresponding acid chloride $\mathbf{4}$ with thionyl chloride in 2-MeTHF and using it directly in the esterification step in the same solvent. Product formation proceeded via formation of the mixed anhydride intermediate 5 that required at least 2 equiv. 3-methylthienyl-2-carboxylic chloride $\mathbf{4}$ for complete conversion. Stoichiometric quantities of this material $\mathbf{4}$ led to much slower and incomplete reactions as esterification of the sterically hindered tertiary alcohol competed with anhydride formation on the acid moiety present in the molecule.

Compound $\mathbf{5}$ was obtained in high purity, even without purification. It was therefore decided that the product would be used as such in the next step. The esterification of the free acid $\mathbf{6}$ was shown to proceed best using 1,8-DBU as a base in 2-MeTHF (Scheme 4). In the case of the more challenging methyl ester formation, dimethyl sulfate was used as the alkylating agent. After the reaction had gone to completion, the excess of dimethylsulfate was reacted with a large excess of morpholine to reduce the total residual amount of alkylating agents to below $5 \mathrm{ppm}$. Compound 7 was originally crystallized from methanol and water. This purification required multiple operations as a solvent switch was necessary, as well as handling of the dried powder. The latest process improvements could however lead to comparable quality of material at that stage in a fully telescoped approach to provide the desired product 7 in $c a .88 \%$ yield and purity $>97 \%$. While the original isolation approach allowed the storage of a stable intermediate, it did not present any further advantages as the purity was neither increased, nor was any specific impurity apparently removed.

At this stage, a fully telescoped process using a single organic solvent had been demonstrated without compromising on the purity of the penultimate intermediate. The last chemical transformation, namely the opening of the epoxide, turned out to be a lot more problematic and challenging.

\section{Ring-opening}

Formation of the $6 \alpha$-chloro side-product 1 ' indeed proved to be a major hurdle (Scheme 5). Its formation that resulted from displacement of the allylic $6 \alpha$-fluoride with retention of configuration made it an inherent process-related impurity. No $6 \beta$-haloisomer was observed as expected due to the poor thermodynamic stability of this isomer. It was also shown that it could not be removed by recrystallization from levels higher than $3 \%$, and therefore had to be limited to below $3 \%$ in the crude reaction mixture to guarantee its complete removal required by the specifications at the Drug Substance stage.

Multiple hydrochloric acid sources were therefore evaluated to minimize its formation. At best, levels around 5\% of the undesired impurity 1' were observed when hydrogen chloride was directly added as gas to a solution of epoxide in toluene at room temperature. These levels could go up to $15 \%$ when the temperature raised even slightly. The amount of the $6 \alpha$-chloro side-product 1' could eventually be significantly reduced when hydrogen chloride was introduced in large excess into the reaction mixture as an isopropanolic solution (Table 3 ). With this simple process change, the amount of the $6 \alpha$-chloro side-product 1 ' could be decreased after extensive optimization down to $0.7 \%$ in the crude reaction mixture when a large excess of $\mathrm{HCl}$ was used (10 equiv.) under kinetic control $\left(0-5^{\circ} \mathrm{C}, 15 \mathrm{~h}\right)$.

Under these optimized conditions, the crude reaction mixture could be directly crystallized from this same 2-MeTHF/iPrOH solvent system to obtain the desired end-product as a transient isopropanol solvate in $65 \%$ isolated yield over the whole five step

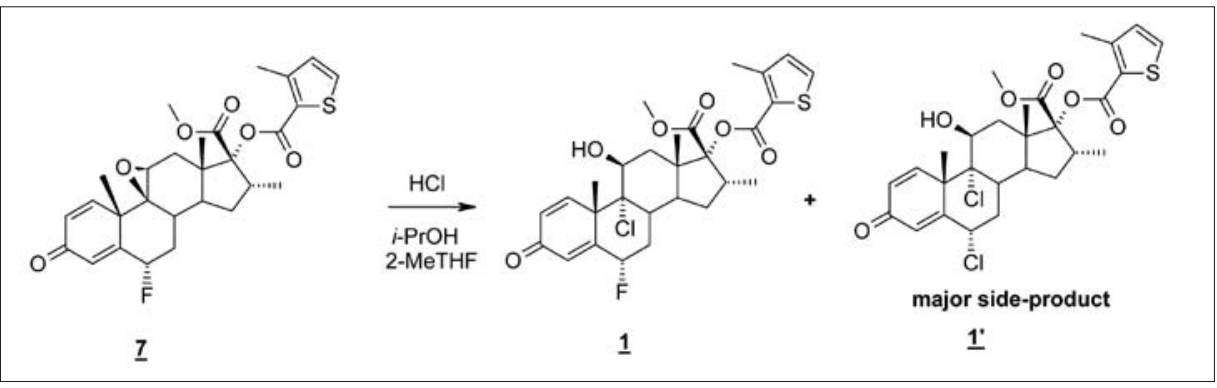

Scheme 5 . Structure of $6 \alpha$-chloro side-product 1 '. 
Table 3. Optimization results

\begin{tabular}{|lllll} 
Entry & $\mathrm{HCl}$ in $i-\mathrm{PrOH} /$ equiv. & Yield & Product 1 ${ }^{\mathrm{a}}$ & $\begin{array}{l}6 \alpha-\text { Chloro } \\
\text { derivative 1'a }\end{array}$ \\
\hline 1 & 6.6 & $74 \%$ & $94.8 \%$ & $1.3 \%$ \\
2 & 9.9 & $74 \%$ & $97.1 \%$ & $0.9 \%$ \\
3 & 13.2 & $78 \%$ & $97.7 \%$ & $0.7 \%$ \\
\hline aHPLC area\% at 210 nm & & &
\end{tabular}

sequence and $98 \%$ purity, similar to the results obtained with the original process.

\section{Discussion}

Throughout the development of this synthesis, a conscious effort was made to find practical ways of improving the safety and environmental impact of the process. Our efforts span over a range of concerns such as the identification of the most efficient synthesis with regard to atom economy and reaction yields, the use of safe and less hazardous chemicals, the elimination and/or reduction of waste as well as the number of operations with the additional goal of reduced exposure to toxic, dry materials. These basic principles, the foundation of green chemistry, are well-known to the scientific community. ${ }^{[13]}$ However, practical examples that illustrate their relevance are still scarce. We therefore wanted to demonstrate quantitatively the relevance of some of the well-accepted green chemistry metrics. The two latest processes will be used for the comparison and discussion, namely the original process with standard isolation of intermediates, referred to as Process A, and the fully streamlined one described above, referred to as Process B (Scheme 6).

As a result of this work, it had proven possible to replace three organic solvents in the original synthesis, namely THF, hexane and toluene with 2-MeTHF. All the intermediates were used in the subsequent steps without purification in the original reaction solvent, 2-MeTHF. This apparently simple change was successful thanks to extensive screening as well as process understanding and greatly impacted the overall productivity of the process.
Although the kinetic of the first oxidative cleavage step slightly increased the individual reaction time, the overall cycle time eventually improved dramatically due to a much reduced number of operations and streamlined work-up protocols. In addition, the new process increased the overall yield from $52 \%$ to $65 \%$, mostly due to reduced mechanical losses (loss of material in the workup and purification steps in the original synthesis, and during the isolation and purification operations). It is worth pointing out that neither Process A nor Process B has really been optimized at this stage. Finally the streamlined synthesis minimized the need to handle dry and toxic material. Interestingly, the primary benefits of the direct isolation process also consisted in the decreased processing costs as very well described by Anderson in an earlier review on the benefits of direct isolation processes. ${ }^{[14]}$

The suitable physical properties of 2-Me-THF, more specifically its polarity, water-immiscibility and azeotropic properties made this change possible. Although slightly more expensive than THF, it eventually turned to be the solvent of choice for our process both from an economic and environmental standpoint.

To illustrate these 'first impressions', we wanted to measure some of the well-accepted green metrics such as the E-factor, the Reaction Mass Efficiency, and the Process Mass Intensity. Sheldon's E-factor ${ }^{[15]}\left(\mathrm{E}_{\mathrm{m}}\right)$ is defined as the mass of total waste per mass of product. The Reaction Mass Efficiency ${ }^{[16]}$ (RME) directly related to the E-factor is defined as $1 /\left(1+\mathrm{E}_{\mathrm{m}}\right)$. The Process Mass Intensity ${ }^{[17]}(\mathrm{PMI})$ is defined as the quantity of raw material input in kilogram per the quantity of bulk API in kilogram. For the latter, several PMIs were calculated on solvents, water, reagents. ${ }^{[13]}$ The first generation of the synthesis was calculated as a convergent sequence due to the formation of the acid chloride that was done in a separate step. The second generation of the synthesis was calculated as a single sequence, as no intermediate was isolated and only assay yields were available. Only the overall yield and the overall waste production were used.

The process is defined as all steps in the synthetic path starting from the readily available epoxyparamethasone. Raw materials are defined as all in-process materials that are used directly in the chemistry of synthesizing, isolating, and purifying the bulk API. The bulk API is the final form of the active ingredient that is produced in the synthesis, dried to the expected specifications, prior

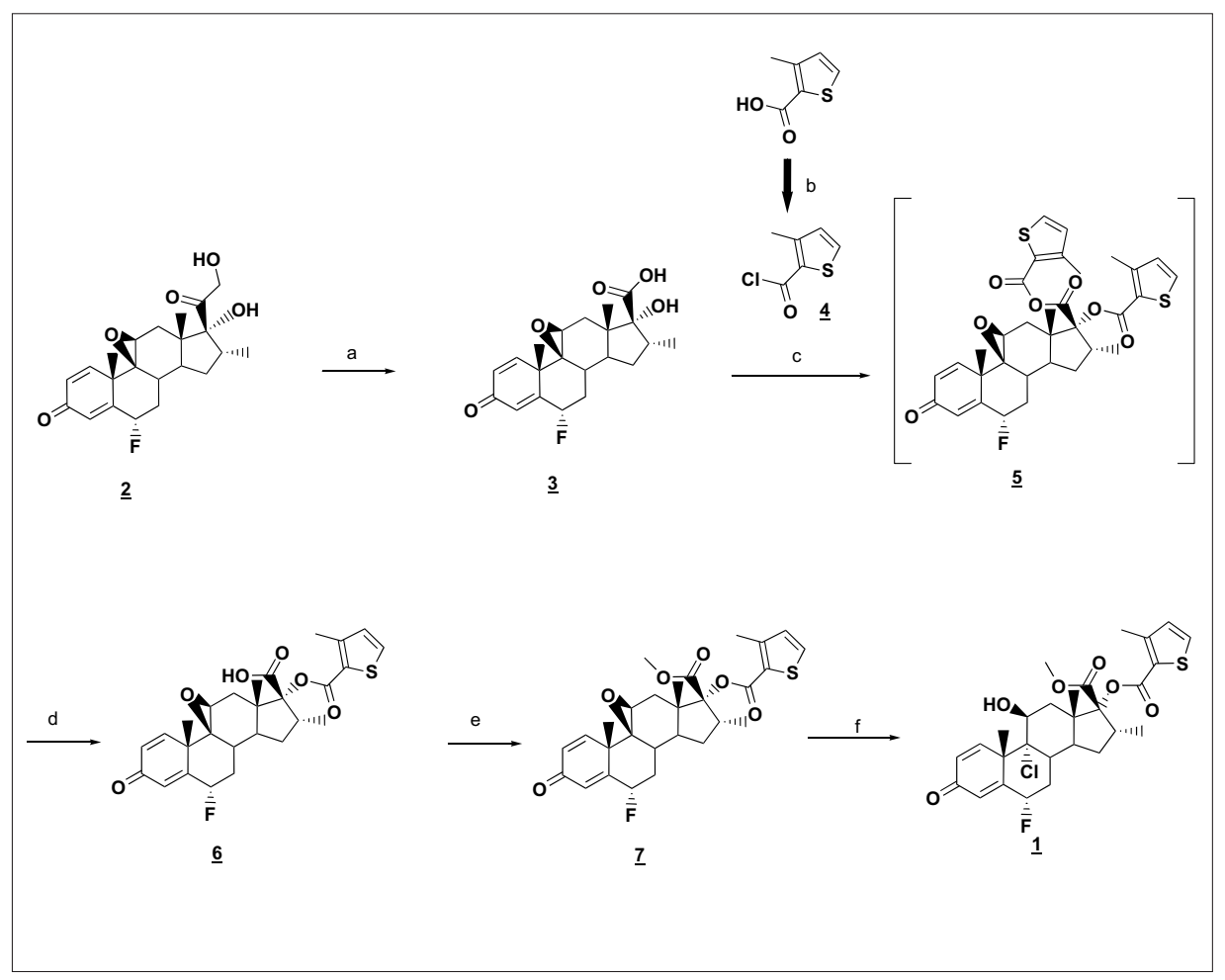

Scheme 6. Process A: a) $\mathrm{H}_{5} \mathrm{IO}$, THF/hexane/ water, rt, $94 \%$; b) $\mathrm{SOCl}_{2}$, toluene, $0-5{ }^{\circ} \mathrm{C}$, quant.; c) pyridine, $\mathrm{THF}, 0-5{ }^{\circ} \mathrm{C}$, then d) $\mathrm{DBU}$, THF, $0-5{ }^{\circ} \mathrm{C}$, and $\mathrm{H}_{2} \mathrm{O}, 84 \%$; e) dimethyl sulfate, THF, $0-5{ }^{\circ} \mathrm{C}, 96 \%$; f) $\mathrm{HCl}$, toluene, $0-5{ }^{\circ} \mathrm{C}, 68 \%$. Process B: a) $\mathrm{H}_{5} \mathrm{IO}_{6}, 2-\mathrm{MeTHF} /$ water, rt, not isolated; b) $\mathrm{SOCl}_{2}, 2-\mathrm{MeTHF}$, rt, not isolated; c) pyridine, 2-MeTHF, not isolated, then d) DBU, 2-MeTHF, $0-5{ }^{\circ} \mathrm{C}$, and $\mathrm{H}_{2} \mathrm{O}$, not isolated; e) dimethyl sulfate, $2-\mathrm{MeTHF}, 0-5{ }^{\circ} \mathrm{C}$, not isolated; f) $\mathrm{HCl}$ in $\mathrm{PrOH}, 2-\mathrm{MeTHF}, 0-5{ }^{\circ} \mathrm{C}, 65 \%$ overall for the six chemical transformations. 
Table 4. Comparison of process A and process B

\begin{tabular}{|c|c|c|}
\hline & Process $\mathrm{A}$ & Process B \\
\hline Yield Step 1 (oxidative cleavage) & $94 \%$ & n.i. \\
\hline Yield Step 2 and 3 (esterification) & $84 \%$ & n.i. \\
\hline Yield Step 4 (esterification) & $96 \%$ & n.i. \\
\hline Yield Step 5 (ring opening) & $68 \%$ & $65 \%$ \\
\hline PMI Step 1 & 51.8 & n.i. \\
\hline PMI Step 2 and 3 & 6.4 & n.i. \\
\hline PMI Step 4 & 44.3 & n.i. \\
\hline PMI Step 5 & 403.1 & 92.9 \\
\hline PMI solvents Step 1 & 9 & n.i. \\
\hline PMI solvents Step 2 and 3 & 35 & n.i. \\
\hline PMI solvents Step 4 & 31 & n.i. \\
\hline PMI solvents Step 5 & 401 & n.i. \\
\hline PMI solvent overall & 476 & 52.8 \\
\hline PMI water Step 1 & 41 & n.i. \\
\hline PMI water Step 2 and 3 & 49 & n.i. \\
\hline PMI water Step 4 & 58 & n.i. \\
\hline PMI water Step 5 & 63 & n.i. \\
\hline PMI water overall & 211 & 31.1 \\
\hline PMI substrates and reagents Step 1 & 2 & n.i. \\
\hline PMI substrates and reagents Step 2 and 3 & 6 & n.i. \\
\hline PMI substrates and reagents Step 4 & 11 & n.i. \\
\hline PMI substrates and reagents Step 5 & 15 & n.i. \\
\hline PMI substrates and reagents overall & 34 & 9 \\
\hline PMI overall & 515.0 & 92.9 \\
\hline $\begin{array}{l}\text { PMI overall predicted with } 80 \% \text { solvent } \\
\text { recycling }\end{array}$ & 515.0 & 50.7 \\
\hline $\mathrm{E}_{\mathrm{m}}$ & 512.7 & 81.6 \\
\hline RME & $0.195 \%$ & $1.21 \%$ \\
\hline Overall yield & $58 \%$ & $65 \%$ \\
\hline
\end{tabular}

to any physical modification steps such as milling or formulation. Atom economy did, of course, not change as exactly the same reactions were used in the two versions of the process. The results, shown in Table 4, clearly show the improvement in ecological impact and reaction mass efficiency for the improved synthesis. Both $\mathrm{E}_{\mathrm{m}}$ and RME have improved by a factor of around 6 . The overall amount of waste in kilogram per kilogram of final product, could be dramatically reduced from $515 \mathrm{~kg} / \mathrm{kg}$ to $93 \mathrm{~kg} / \mathrm{kg}$. During the synthesis solvents and reagents were not recovered, which could provide another point of improvement for the process in the future. With $80 \%$ recycling efficiency in process B for example, the overall PMI would be further reduced to $c a .51 \mathrm{~kg}$ / $\mathrm{kg}$. Recycling would not be realistic in process A.

A cost of goods analysis was also made to evaluate the evolution of the cost with the new process. Processing costs, which would further reemphasize the benefit of direct isolation process $\mathrm{B}$, were omitted. The price calculation was made in US dollars based on prices taken directly from the common vendors (Sigma Aldrich). The streamlined process B turns to be more advantageous, despite the omission of processing costs. While the first two steps turned to be more expensive than in process A that used cheaper solvents, it was significantly compensated by the more efficient processes used in the subsequent steps. The minimized mechanical losses also helped bringing down the overall cost ultimately by a factor 3 (Table 5).
Table 5. Costs comparison between the two processes

\begin{tabular}{|lllll|} 
& $\begin{array}{l}\text { Process A } \\
\text { COG (USD) } \\
\text { / kg end- } \\
\text { product }\end{array}$ & $\begin{array}{l}\text { Cost per } \\
\text { step } \\
\text { (USD) }\end{array}$ & $\begin{array}{l}\text { Pocess B } \\
\text { (USD) / } \\
\text { kg end- } \\
\text { product }\end{array}$ & $\begin{array}{l}\text { Cost per } \\
\text { step } \\
\text { (USD) }\end{array}$ \\
\hline Step 1 & 3.9 & 129.5 & - & 172.8 \\
Step 2 and 3 & 10.7 & 355.6 & - & 429.6 \\
Step 4 & 5.3 & 181.8 & - & 21.1 \\
Step 5 & 13.9 & 674.1 & - & 26.6 \\
Overall & 44.4 & 1340.9 & 13.4 & 650.1 \\
\hline COG: Cost of Goods & & & \\
\hline
\end{tabular}

\section{Conclusion}

The development of a streamlined process for our androstadiene C-17 ester candidates led us to identify a fully streamlined process that utilized only two solvents over five steps and a single isolation of the end product. The overall amount of waste in kilogram per kilogram of final product, could be dramatically reduced. The improved ecological impact was also in accordance with a reduced overall cost. Finally, the new process allowed for much improved personal safety as it removed the need for isolation and handling of highly active intermediates. We hope that this successful example of the application of the principles of Green Chemistry will be regarded as a useful example by the scientific community and that the concept will be further used particularly in the context of highly active compounds.

\section{Experimental Section}

\section{$(6 \alpha, 9 \beta, 11 \beta, 16 \alpha, 17 \alpha)-9,11-e p o x y-6-f l u o r o-17-h y d r o x y-$ 16-methyl-3-oxo-Androsta-1,4-diene-17-carboxylic acid (3)}

Epoxyparamethasone (2) (99.6 g, $255 \mathrm{mmol}, 1.0$ equiv.) was suspended in 2-MeTHF $(0.8 \mathrm{~L})$ and a freshly prepared aqueous solution of periodic acid $(81.4 \mathrm{~g}, 357 \mathrm{mmol}, 1.4 \mathrm{eq}$ into $0.22 \mathrm{~L}$ water) was added at a rate such that the temperature remained below $30^{\circ} \mathrm{C}$ ( $\mathrm{ca} .15 \mathrm{~min}$ addition). After the conversion is complete (about $12 \mathrm{~h}$ ), the phases were separated, and the organic phase was washed twice with $0.25 \mathrm{~L}$ water. The water washings were combined and kept separately. The organic phase was then washed twice with an aqueous phosphinic acid solution $(33 \mathrm{~mL}$ of the commercial 50\% phosphinic acid solution in water, further diluted with $0.23 \mathrm{~L}$ water). It is critical that these washings are kept separately and not combined with the previous water extracts as phosphinic acid would react violently with the excess periodic acid. At this point, no peroxide was observed in the organic phase. The crude solution was then concentrated to $c a$. half the volume under reduced pressure ( $c a$. 300-400 mbar, internal temperature $c a$. 50-55 ${ }^{\circ} \mathrm{C}$ ). An equal amount of dry 2-MeTHF ( $c a .0 .5 \mathrm{~L}$ ) was added and the azeotropic distillation was repeated twice more to result in a dry crude solution of product in 2-MeTHF (Assay yield: $94 \%$, purity: ca. $96 \%$ by HPLC). ${ }^{1} \mathrm{H}$ NMR (DMSO-d6, $\left.400 \mathrm{MHz}\right) 0.84$ (d, J=7.2 Hz, 3H), 0.88 (s, $3 \mathrm{H}), 1.18-1.24(\mathrm{~m}, 1 \mathrm{H}), 1.36$ (s, 3H), 1.38-1.72 (m, 3H), 2.18 (d, $J=13.5 \mathrm{~Hz}, 2 \mathrm{H}), 2.30$ (ddd, $J=10.8,7.8,6.5 \mathrm{~Hz}, 2 \mathrm{H}), 2.56-2.64$ (m, 2H), 2.71-2.79 (m, 1H), 3.33 (br s, 1H), 5.62-5.78 (2m, 1H), $6.15(\mathrm{~d}, J=2.0 \mathrm{~Hz}, 1 \mathrm{H}), 6.18$ (s, 1H), 6.60 (dd, $J=9.8,1.3 \mathrm{~Hz}, 1 \mathrm{H})$.

$(6 \alpha, 9 \beta, 11 \beta, 16 \alpha, 17 \alpha)-9,11$-epoxy-6-fluoro-16-methyl17-[[(3-methyl-2-thienyl)carbonyl]oxy]-3-oxo-Androsta-1,4-diene-17-carboxylic acid methyl ester (7)

Preparation of 3-methyl-2-thiophenecarbonyl chloride (4): 3-methylthienyl-2-carboxyl acid (79 g, 0.56 mol, 2.1 equiv.) was dis- 
solved into 2-MeTHF $(0.3 \mathrm{~L})$ and cooled to $0{ }^{\circ} \mathrm{C}$. Thionyl chloride ( $151 \mathrm{~g}, 92 \mathrm{~mL}, 1.27 \mathrm{~mol}, 2.4$ equiv.) was added at rate such that the temperature remained below $5{ }^{\circ} \mathrm{C}$ ( $\mathrm{ca} .15$ min addition) and the resulting mixture was stirred at that temperature for $1 \mathrm{~h}$ and used as such in the subsequent transformation.

To the freshly prepared solution of $\mathbf{3}(\mathrm{ca} .100 \mathrm{~g}, \mathrm{ca} .0 .27 \mathrm{~mol})$ in 2-MeTHF (0.45 L) was added dry pyridine (147.5 g, 7.3 equiv.), and the freshly prepared solution of 3-methyl-2-thienyl carboxyl chloride 4 (freshly prepared solution from above) was added at a rate such that the temperature remained below $5{ }^{\circ} \mathrm{C}(\mathrm{ca} .30$ min addition). The mixture was stirred for an additional $2 \mathrm{~h}$ at $0-5{ }^{\circ} \mathrm{C}$. Water (ca. $0.4 \mathrm{~L}$ ) and dbu (102 g, $670 \mathrm{mmol}, 2.5$ equiv.) were added in $c a .15 \mathrm{~min}$ at that temperature and the resulting mixture was stirred at that temperature for $c a .2 \mathrm{~h}$, until complete hydrolysis of the mixed anhydride. The $\mathrm{pH}$ was adjusted to $1-1.5$ by addition of hydrochloric acid, and the aqueous layer was removed. Dimethyl sulfate (95 g, $750 \mathrm{mmol}, 2.8$ equiv.) was added at that temperature and the resulting mixture was stirred for $15 \mathrm{~h}$ until complete methyl ester formation, quenched with the addition of morpholine (58 g, $665 \mathrm{mmol}, 2.5$ equiv.) and stirred for an additional $30 \mathrm{~min}$. The reaction mixture was quenched with water $(0.2 \mathrm{~L})$ and the aqueous layer was removed. The organic layer was washed with water $(0.2 \mathrm{~L})$, dilute $\mathrm{HCl}(2 \mathrm{M}, 0.2 \mathrm{~L})$, and brine $(0.2 \mathrm{~L})$. The resulting organic extract was concentrated to $c a$. half the volume under reduced pressure to afford the desired product 7 in $c a .88 \%$ assay yield and ca. $97 \%$ purity. ${ }^{1} \mathrm{H}$ NMR (DMSO-d6, $400 \mathrm{MHz}) 0.90$ (d, J=7.2 Hz, 3H), 0.91 (s, 3H), 1.20-1.26 (m, $1 \mathrm{H}), 1.39(\mathrm{~s}, 3 \mathrm{H}), 1.50-1.93(\mathrm{~m}, 2 \mathrm{H}), 2.20-2.32(\mathrm{~m}, 1 \mathrm{H}), 2.41(\mathrm{~s}$, $3 \mathrm{H}), 2.46-2.75(\mathrm{~m}, 3 \mathrm{H}), 3.16-3.37(\mathrm{~m}, 1 \mathrm{H}), 3.57-3.84(\mathrm{~m}, 1 \mathrm{H})$, $3.65(\mathrm{~s}, 1 \mathrm{H}), 3.78(\mathrm{~s}, 3 \mathrm{H}), 5.63-5.79(\mathrm{~m}, 1 \mathrm{H}), 6.19(\mathrm{dd}, J=1.8$, $10.1 \mathrm{~Hz}, 1 \mathrm{H}), 6.25(\mathrm{~s}, 1 \mathrm{H}), 6.57-6.65(\mathrm{~m}, 1 \mathrm{H}), 7.05(\mathrm{~d}, J=5.0 \mathrm{~Hz}$, $1 \mathrm{H}), 7.13-7.25(\mathrm{~m}, 1 \mathrm{H}), 7.74(\mathrm{t}, J=6.1 \mathrm{~Hz}, 1 \mathrm{H})$.

\section{$(6 \alpha, 11 \beta, 16 \alpha, 17 \alpha)-9$-chloro-6-fluoro-11-hydroxy-16- methyl-17-[[(3-methyl-2-thienyl)carbonyl]oxy]-3-oxo- Androsta-1,4-diene-17-carboxylic acid, methyl ester (1)}

To a solution of compound 7 (crude mixture from above) in 2-MeTHF ( $c$ a. 0.5 L) was added a $6.8 \mathrm{M}$ solution of hydrogen chloride in $i$ - $\mathrm{PrOH}(0.5 \mathrm{~L}, 3.4 \mathrm{~mol}, 13.2$ equiv. $)$ at $0-5{ }^{\circ} \mathrm{C}$ in 30 min. The solution was stirred for $15 \mathrm{~h}$ until completion. The mixture was concentrated to $\mathrm{ca}$. half volume under reduced pressure (ca. 100 mbar, internal temperature $c a .55^{\circ} \mathrm{C}$ ) and the process was repeated after addition of $c a .0 .2 \mathrm{~L}$ of $i$-PrOH. An additional $0.1 \mathrm{~L}$ of $i$-PrOH was added and the mixture was heated to $c a .60$ ${ }^{\circ} \mathrm{C}$, and seeded with the pure $i$-PrOH solvate. The mixture was aged for $1 \mathrm{~h}$, and cooled linearly to $0{ }^{\circ} \mathrm{C}$ in $6 \mathrm{~h}$. The precipitate was filtered off and washed with cold $i-\mathrm{PrOH}(0.1 \mathrm{~L})$. Drying at $40{ }^{\circ} \mathrm{C}$ afforded $c a .90 \mathrm{~g}$ of the pure $i$-PrOH solvate $\mathbf{1}$ as a white powder in $78 \%$ yield and $97 \%$ purity. ${ }^{1} \mathrm{H}$ NMR (DMSO-d6, $400 \mathrm{MHz}) 0.90(\mathrm{~d}, J=7.2 \mathrm{~Hz}, 3 \mathrm{H}), 1.00(\mathrm{~s}, 3 \mathrm{H}), 1.20-1.26(\mathrm{~m}$, $1 \mathrm{H}), 1.61(\mathrm{~s}, 3 \mathrm{H}), 1.62-1.72(\mathrm{~m}, 1 \mathrm{H}), 1.85-1.93(\mathrm{~m}, 1 \mathrm{H}), 2.23-$ $2.27(\mathrm{~m}, 1 \mathrm{H}), 2.43(\mathrm{~s}, 3 \mathrm{H}), 2.46-2.55(\mathrm{~m}, 3 \mathrm{H}), 2.75(\mathrm{dt}, J=3,0$, $8.0 \mathrm{~Hz}, 1 \mathrm{H}), 3.25-3.31(\mathrm{~m}, 1 \mathrm{H}), 3.65$ (s, 3H), 4.39 (br s, 1H), $5.53-5.71(\mathrm{~m}, 1 \mathrm{H}), 5.65(\mathrm{~d}, J=11.5 \mathrm{~Hz}, 1 \mathrm{H}), 6.11(\mathrm{~s}, 1 \mathrm{H}), 6.29$ $(\mathrm{dd}, J=2.0,10.3 \mathrm{~Hz}, 1 \mathrm{H}), 7.04(\mathrm{~d}, J=5.0 \mathrm{~Hz}, 1 \mathrm{H}), 7.28$ (dd, $J=1.5$, $10.1 \mathrm{~Hz}, 1 \mathrm{H}), 7.75(\mathrm{~d}, J=4.7 \mathrm{~Hz}, 1 \mathrm{H}) ;{ }^{13} \mathrm{C}$ NMR (DMSO-d6, 100 MHz) $15.5,16.2,16.9,24.1,32.6,33.8,33.9,35.9,36.0,40.1$, 48.7, 49.8, 51.8, 73.7, 83.8, 85.8, 87.5, 91.8, 119.5, 124.9, 128.7, 132.2, 146.6, 151.9, 160.9, 162.6, 169.1, 184.4; HRMS (M+H) calcd 551.16700, obsd 551.16636.

Received: October 2, 2011

[1] D. A. Sandham, L. Barker, D. Beattie, D. Beer, L. Bidlake, D. Bentley, K D. Butler, S. Craig, D. Farr, C. Ffoulkes-Jones, J. R. Fozard, S. Haberthuer, C. Howes, D. Hynx, S. Jeffers, T. H. Keller, P. A. Kirkham, J. C. Maas,
L. Mazzoni, A. Nicholls, G. E. Pilgrim, E. Shaebulin, G. M. Spooner, R. Stringer, P. Tranter, K. L. Turner, M. F. Tweed, C. Walker, S. J. Watson, B. M. Cuenoud, Bioorg. Med. Chem. 2004, 12, 5213; Novartis Pharma AG, B. Cuenoud, D. Beattie, T. H. Keller, G. E. Pilgrim, D. A. Sandham, S. J. Watson, WO2002/00679 A2; Novartis Pharma AG, G. Jordine, M. Mutz, WO2004/013156 A1

[2] D. J. Kertesz, M. Marx, J. Org. Chem. 1986, 51, 2315.

[3] L. Pacesova, Z. Hauptman, Z. Anorg. Allg. Chem. 1963, 325, 325; O. N. Breusov, N. I. Kashina, T. V. Revzina, Zh. Neorg. Khim. 1970, 15, 612.

[4] J. Schmidlin, Chem. Abstract 1985, 103, 105215.

[5] 'Periodic Acid', 'Encyclopedia of Reagents for Organic Synthesis', Wiley \& Sons, Posted September 15, 2006. http://onlinelibrary.wiley.com/o/eros/ articles/rn00561/pdf fs.html

[6] Methyl periodate is a reported explosive. See B. Martel, 'Chemical risk analysis: a practical handbook', Hermes Penton, London, UK, 2004, p. 280.

[7] T. Takata, R. Tajima, W. Ando, J. Org. Chem. 1983, 48, 4764; P. Ferraboschi, M. N. Azadani, E. Santaniello, S. Trave, Synth. Commun. 1986, 16, 43.

[8] F. D. Albinson, S. J. Coote, J. M. Robinson, J. Malcolm, PCT Int. Appl. 2002, WO 200200843 A1 20020131.

[9] K. V. S. Rao, K. V. S. Rama, A. V. Sapre, Radiation Effects 1970, 3, 183; V. G. Glukhovtsev, G. I. Zaitseva, Y. V. Il'in, J. Org. Chem. USSR 1981, 17, 438; V. G. Glukhovtsev, Y. V. Il'in, G. I. Nikhishin, Bull. Acad. Sci. USSR Div. Chem. Sci. 1983, 32, 1479; Y. V. Il'in, V. A. Platkhotnik, V. G. Glukhovtsev, G. I. Nikhishin, Bull. Acad. Sci. USSR Div. Chem. Sci. 1982, 31, 1976; E. M. Kuramshin, V. K. Gumerova, S. S. Zlot-skii, D. F. Rakhmankulov, V. G. Glukhovtsev, J. Gen. Chem. USSR 1983, 53, 148; V V. Zorin, S. S. Zlot-skii, V. G. Glukhovtsev, Y. V. Il'in, G. I. Nikhishin, D. F. Rakhmankulov, J. Org. Chem. USSR 1981, 17, 231; K. Griesbaum, G. H. Mertens, P. Krieger-Beck, H. Henke, Can. J. Chem. 1994, 72, 2198; G. I. Nikhishin, et al. Bull. Acad. Sci. USSR Div. Chem. Sci. 1971, 20, 2202.

[10] S. Baj, Fresenius J. Anal. Chem. 1994, 350, 159.

[11] The new solvent system 2-MeTHF/water allowed us to start the drying with a water content twice as low as with the former solvent system THF/ heptane/water ( $\mathrm{ca} .5 \%$ residual water instead of $>10 \%$ ). Besides, the azeotropic drying proceeded within 2 cycles instead of 4 or 5 typically required in the presence of THF, in the absence of a rectification column.

[12] Boiling point azeotrope $71^{\circ} \mathrm{C}$ at atmospheric pressure, $89.4 \mathrm{wt} \%$ solvent, $10.6 \mathrm{wt} \%$ water

[13] P. Anastas, J. Warner, 'Green Chemistry: Theory and Practice', Oxford University Press, Oxford, UK, 1998, p. 30.

[14] N. G. Anderson, Org. Proc. Res. Dev. 2004, 8, 260

[15] R. A. Sheldon, Chem. Ind. (London), 1992, 903.

[16] J. Andraos, Org. Process. Res. Dev. 2005, 9, 149; J. Andraos, Org. Process. Res. Dev. 2005, 9, 404.

[17] C. Jimenez-Gonzalez, C. S. Ponder, Q. B. Broxterman, J. B. Manley, Org. Process. Res. Dev. 2011, 15, 912. 